\title{
PREVENTION OF TAXI ACCIDENTS IN XI'AN, CHINA: WHAT MATTERS MOST?
}

\author{
Yonggang Wang ${ }^{1}$, Ming $\mathrm{Li}^{1}$, Jianhua $\mathrm{Du}^{2}$, Chengyuan $\mathrm{Mao}^{3}$ \\ 'School of Highway, Chang'an University, Xi'an, China \\ ${ }^{2}$ International Engineering Department, Shijiazhuang Institute of Railway Technology, Shijiazhuang, China \\ ${ }^{3}$ College of Engineering, Zhejiang Normal University, Jinhua, China
}

\section{SUMMARY}

Objectives: Since the city of Xi'an has been extremely concerned with the serious problem of taxi involved crashes, injuries and fatalities, the primary purpose of this study is to identify the risk factors associated with the magnitude and nature of the problem and provide possible measures for enhancing the overall safety performance of taxi industry.

Methods: Using 726 crash samples from the original of 7,183 observations in Xi'an over the period from 2006 to 2012, comparative statistics and systematic analysis were employed to describe the distribution of taxi crashes by driver characteristics, roadway contributors and environmental factors and then determine the significant factors contributing to crash injuries and fatalities.

Results: The trend and pattern of taxi involved crashes vary significantly. Middle aged $(77.27 \%)$ male $(91.60 \%)$ drivers with limited education $(68.59 \%)$ and less driving (31.27\%) and job (82.50\%) experience were much more likely to be involved in such a crash. Additionally, it is found that a large majority of taxi crashes occurred with the most frequent type of rear end collisions (30.72\%), on six-lane segments without median (16.94\%) or four legged intersections $(15.29 \%)$, under adverse weather conditions $(31.82 \%)$, at weekends $(34.99 \%)$, and during winter days $(34.72 \%)$, but fatal and serious crashes were more likely to happen at night $(30.72 \%)$ or under wet road surface conditions (16.94\%), due to driver's overspeeding, unbelted, disregarding signs or signals, or other types of risk driving behaviour.

Conclusions: The risk of taxi related crashes varies by drivers, roadways and environment. To reduce the risk of potential crashes for taxi drivers, we recommend the targeted legislation and enforcement, stronger night and trip restrictions, awareness of risk behaviour, and periodical training requirement. Such proposals and measures are expected to help mitigate taxi crashes and promote road safety in China.

Key words: taxi crash, risk factor, roadway contributor, environmental factor, driving behaviour, road safety

Address for correspondence: Y. G. Wang, School of Highway, Chang'an University, P.O. Box 487, Middle Section of South 2 Ring Rd., Xi'an 710064, China. E-mail: wangyg@chd.edu.cn

\section{INTRODUCTION}

Over the past three decades, the rapid expansion of China's economy has lead to dramatically increasing urbanization and motorization and an alarm growth in road traffic injuries and fatalities. Particularly, the amount of motor vehicles in China has increased from 108 million units in 2004 to 207 million units in 2010, an average rate of $11.49 \%$ per year. In 2010 , however, 219,512 crashes occurred with 254,075 injuries and 65,225 fatalities, $40.37 \%$ lower than the peak year of 2002 , due to a series of national safety improvement programmes (1). Theoretically, professional taxi, bus or lorry drivers are at a greater risk of being involved in a vehicle crash, due to their occupational exposure to hazardous fatigue and stress (2). With the huge amount of the professional groups all over the world, it represents widely shared concerns about this occupational health issue.

Given the significant effect of exposure to hazardous environments on the health of taxi drivers, some researchers have also emphasized their importance for the occupational related risk factors contributing to the occurrence of crashes, including socio-demographic characteristics of drivers involved (3), driving experience (4), fatigue (5), sleepiness (6), vision damage (7), mental stress (8), duration of working hours (9), and thus analyzed the major causes. La et al. reported that taxi crashes are related to the driver's age, type of license, employment status (full or part time), satisfaction with pay, and seat-belt usage (10). Lam found that females confronted significantly higher risk of injuries and fatalities due to crashes, compared with their male counterparts, and it was even more serious for those who work in night or do not carry passengers (2). Newnam et al. found that older, more educated taxi drivers were more likely to commit unsafe driving behaviour in Addis Ababa, Ethiopia, due to the cultural ideologies of the region (11). Dalziel and Job found that busy or workload taxi drivers were more likely to be involved in a crash due to stress than those with more break time during the working day (12), and similar findings were also reported by $\mathrm{Oz}$ et al. (13).

Behaviour of taxi drivers makes a significant contribution to the involvement in a crash. In Nanjing, China, the taxi drivers were found to be less likely to use seat belt (14), and similar survey results were also reported in Beijing (15), but the use or misuse of seat belts is still not fully understood. The findings from 248 taxi and bus drivers in Wuhan, China highlighted that risky driving behaviour was significantly affected by their attitudes toward traffic rules and speed (16). Sullman et al. reported that taxi drivers more often engaged in passive-aggressive behaviour significantly related to possible crashes, losing control of the vehicle, loss of concentration, and near-misses (17). Since health and safety training play a key role among taxi drivers, it 
is necessary to impose strict laws and initiate rigorous enforcement programmes for reducing and preventing their improper/ illegal driving behaviour (18). Tseng revealed that a taxi driver's speeding violation is significantly related to age, job experience, operating styles, kilometers driven daily, driving late at night, and monthly off duty days in Taiwan (19).

Due to rapid economic development and urbanization during the past decade, Xi' an is significantly motorized, and the number of four wheeled motor vehicles dramatically increased from 143,799 in 2001 to 1,153,521 in 2011. During this period, the taxi industry has proved a great success with superior quality of services and has grown successfully to a profitable business, which, as a result, increased the number of licensed taxi vehicles (20). There are at least 22 taxi companies providing service in Xi'an today, with sizes ranging from less than 100 taxis to over 1,100 , plus a number of unlicensed vehicles. In the year of 2011 , approximately 50 taxi involved crashes occurred per day. Of course, taxi drivers are confronted with more dangerous driving environment compared with other car drivers, and they have to spend long periods on the road under greater stress. Notably, they more frequently commit violations, such as unsafe lane changing, risky overtaking, and fatigued driving etc., in order to save time and earn more money, and thus it is no surprise that they are more likely to be involved in crashes. However, few studies have focused on the safety related issues of taxi traffic during the previous decade, especially in the developing countries, such as China and India.

Accordingly, the primary purpose of this study aims at analyzing the crash characteristics associated with taxi services in Xi'an, China, in order to identify the major contributory factors to such problems and then propose countermeasures. Our corresponding findings will shed light on the development of effective traffic legislation and technical measures targeting taxi traffic to help reduce injuries caused by accidents and promote road safety in Chinese cities.

\section{MATERIALS AND METHODS}

The original crash data in Xi' an over the period of 2006-2012 is obtained from the Traffic Accident Database System released by the Ministry of Public Security of the People's Republic of China and maintained by the local Police Force and Transport Department. This system provides precise crash messages in three profiles: crash environment, casualty/injury and vehicle involvement. The crash environment profile gives the data, time and location of crash occurrence, weather conditions, traffic flow states, roadway geometrics, percentage of heavy trucks, and status of traffic facilities, etc.

In the original accident database, the crash injury is divided into three levels: fatal, serious and slight: fatal injury refers to crashes that result in immediate death or subsequent death within 30 days of the accident; serious injury refers to crashes that require hospitalization for 2 weeks or more; and slight injury refers to crashes that require hospitalization for 24 hours or less, or no hospitalization at all. Crash types are divided into several categories: head-on, sideswipes, rear end, rollovers, collision with fixed objects, collision with pedestrians and bicyclists, and other types. Moreover, the police record also gives a detailed crash story about the interpreted comments from the attending police officers, photographs, statements of vehicle examiners, interviews and witnesses, which supplement rich information in reconstructing the entire crash process and identifying the potential factors that have contributed to the occurrence of crashes.

A sample of 7,183 original crash cases during the recent seven-year period of 2006-2012 is selected from the Xi' an Traffic Police Department official database. Unfortunately, some necessary information was sometimes missing or incomplete in the crash records (e.g. the condition of road surface, control pattern of intersection, etc.). Thus, 322 records accounting for $4.48 \%$ of the original collection were removed from the computerized crash system and the left 6,861 samples were used for the further analysis. Then a careful review of these selected crash data was performed to check and identify the taxi involved crash records that occurred in Xi'an during 2006-2012 and 726 valid reports (head-on collision $12.95 \%$, sideswipes $22.45 \%$, rear-end collision $30.72 \%$, rollovers $6.61 \%$, collision with fixed objects $14.74 \%$, collision with pedestrians and bicyclists $10.33 \%$, and other types $4.68 \%$ ) were finally obtained, out of which $13.41 \%$ proved fatal, $28.57 \%$ resulted in serious injuries and the rest in slight injuries.

\section{RESULTS}

\section{Driver Characteristics}

Table 1 shows the statistical characteristics of taxi crashes. Clearly, middle aged male taxi drivers are more frequently involved in crashes, mainly because the majority of taxi driver's jobs were associated with males in most China cities, especially with those aged between 25 and 45 years. But during recent years, this trend has changed with more females engaging in the taxi service.

In addition, the risk perception skills of drivers significantly affect the occurrence of crashes. Males are believed to have superior driving skills in catching the danger ahead, controlling the vehicles and escaping dangerous situations, and thus they are less likely than female counterparts to be involved in a fatal crash. However, males tend to adopt hazardous driving behaviour (e.g. not using seat belts, fatigue, mobile use while driving) more than female drivers, and carelessness and extraction in driving also induce male drivers to perceive lower risk than females while watching the roadway geometrics and environment.

In view of driver's age, the mean is 34.62 years with a standard deviation of 6.73 years. As shown in Table 1, the distribution of drivers by age shows that the largest age group is between 25 and 35 years and about $49.17 \%$ of the taxi drivers are involved in crashes. In addition, the age groups of 35-45 and 18-25 years old have the second and third highest frequency of crashes, respectively.

Marital status and education level are identified as other major factors affecting the occurrence of crashes. Among the reviewed 726 samples, 116 unmarried, divorced or widowed drivers, accounting for $15.98 \%$ of total records, have been involved in crashes, indicating that a nice family life helps maintain peace of mind and decreases the likelihood of crash involvement. Among all taxi drivers involved, only $2.34 \%$ have a higher education - specific bachelor degree or higher, while nearly one-third of them have received primary education programmes or even are 
Table 1. Socio-demographic characteristics of taxi drivers

\begin{tabular}{|c|c|c|}
\hline Variable & $\mathbf{N}$ & $\%$ \\
\hline \multicolumn{3}{|l|}{ Gender } \\
\hline Male & 665 & 91.60 \\
\hline Female & 61 & 8.40 \\
\hline \multicolumn{3}{|l|}{ Age (years) } \\
\hline$<18$ & 5 & 0.69 \\
\hline $18-25$ & 112 & 15.43 \\
\hline $25-35$ & 357 & 49.17 \\
\hline $35-45$ & 204 & 28.10 \\
\hline $45-55$ & 41 & 5.65 \\
\hline$>55$ & 7 & 0.96 \\
\hline \multicolumn{3}{|l|}{ Marital status } \\
\hline Married & 610 & 84.02 \\
\hline Unmarried $^{1}$ & 116 & 15.98 \\
\hline \multicolumn{3}{|l|}{ License } \\
\hline Invalid $^{2}$ & 65 & 8.95 \\
\hline Valid $^{3}$ & 661 & 91.05 \\
\hline \multicolumn{3}{|l|}{ Education background } \\
\hline Illiterate & 58 & 7.99 \\
\hline Primary school & 123 & 16.94 \\
\hline Middle school & 317 & 43.66 \\
\hline Junior high school & 211 & 29.06 \\
\hline Higher education & 17 & 2.34 \\
\hline \multicolumn{3}{|l|}{ Driving experience ${ }^{4}$} \\
\hline Novice & 227 & 31.27 \\
\hline Practician & 332 & 45.73 \\
\hline Proficient & 118 & 16.25 \\
\hline Expert & 49 & 6.75 \\
\hline \multicolumn{3}{|l|}{ Job experience } \\
\hline$<2$ & 339 & 46.69 \\
\hline $2-5$ & 260 & 35.81 \\
\hline $5-10$ & 94 & 12.95 \\
\hline$>10$ & 33 & 4.55 \\
\hline
\end{tabular}

Single, divorced, and widow.

${ }^{2} \mathrm{PDL}, \mathrm{GDL}$ out of validity, and no license.

${ }^{3} \mathrm{GDL}$ within validity.

${ }^{4}$ Measured in years, and classified into four groups: novice ( $\leq 3$ years), practician ( $3-5$ years), proficient (6-15 years), and expert ( $\geq 15$ years)

illiterate, and most of the involved taxi drivers have a middle or junior high school education background, accounting for $72.72 \%$ of the total samples.

In the previous studies, sufficient evidence was gathered to prove that drivers licensing influences the frequency of crashes involved $(21,22)$. Accordingly, there is a clear and strict governmental regulation requiring that the taxi driver must carry a General Driving License (GDL)* while driving a taxi vehicle, and it is illegal to work with a Private Driving License (PDL)*. In addition, drivers aged below 18 years are prohibited to hold any license. Among the 65 cases with invalid license, 47 were found to hold PDL, since these drivers with PDL have joined in the taxi companies with their private cars, and the licensed process and annual taxi inspection are not supervised effectively and present law enforcement is not sufficient to get them off the work. The other cases with invalid license include 7 with GDL out of validity and 11 without license.

Like the age, both driving experience and job experience are found to have significant impact on the ability of risk perception and response affecting crash occurrence. Novice (1-3 years of driving experience) and practician (3-5 years of driving experience) taxi drivers are more likely to be involved in a crash, accounting for $77.00 \%$ of all observations, because of their lower knowledge and immaturity in dealing with potential dangers and emergency conditions. Similarly, those with less than two years job experience exhibit the highest proportion of involvement in fatal crashes (46.69\%), following by those with $2-5$ years $(35.81 \%)$.

According to the original records in accident database, Table 2 presents the frequencies of improper driving behaviour that contributed to the occurrence of taxi crashes. From the statistics, nine risk or illegal behaviours of drivers with the highest frequency were identified and appeared 1,356 times in the 726 sample of crashes. That is, the proportion of these most frequent behaviours is $1.87(1,356 / 726)$ per crash, and it is even much worse for the fatal and serious crashes, since the similar level of risk increases to $2.88(878 / 305)$.

In addition, driving too fast or over speed limits is the most dangerous and illegal behaviour and it appeared in nearly 50\% of the study samples and over $77 \%$ of the fatal and serious ones, respectively. The frequency of safety belt not used and disregarding signs or signals are both too high to be neglected in driving education and daily traffic management.

\section{Roadway Contributors}

Among the audited 726 crashes, 329 and 202 cases occurred on urban arterials and sub-arterials, representing $43.5 \%$ and $26.3 \%$ of all crashes, respectively. Specially, three expressways (Ring 2 Rd., Ring 3 Rd., and Raocheng expressway) had an average of 16.29 crashes annually from 2006 to 2012 , accounting for $15.70 \%$ of the total cases reported during this period.

The type or pattern of roadway segments and intersections was closely associated with the occurrence of crashes, including taxi involved cases, because the geometric designs of segments and intersections affect the vision scope, speed choice and risk perception of drivers and distribution of traffic volume (23). In this study, we explored the distributions of taxi crashes according to the types of segments by the number of dividers and intersections, in which intersection's influence area was limited within $50 \mathrm{~km}$ along the entrance lanes (Table 3).

As shown in Table 3, 470 cases or $64.74 \%$ of the total records occurred on the segments, and a relatively large proportion of crashes occurred on undivided six-lane segments (16.94\%) and four legged intersections (15.29\%), followed successively by those on eight-lane segments $(11.30 \%)$ and four-lane segments without median (10.61\%).

*A General Driving License (GDL) allows the license holder to drive any vehicle for commercial use (passenger vehicles for hire such as a taxi, bus, van, limousine; trucks which transports goods or hazardous materials, while a Private Driving License (PDL) holder is only allowed to drive private vehicles. 
Table 2. Frequency of risk driving behaviours in taxi crashes

\begin{tabular}{|c|c|c|c|c|}
\hline \multirow{2}{*}{ Driving behaviours } & \multicolumn{2}{|c|}{ Total crash } & \multicolumn{2}{|c|}{ Fatal and serious crash } \\
\hline & Count & Frequency & Count & Frequency \\
\hline Driving over speed limits & 368 & 0.507 & 223 & 0.731 \\
\hline Safety belt not used & 297 & 0.409 & 257 & 0.843 \\
\hline Disregarding signs or signals & 145 & 0.200 & 90 & 0.295 \\
\hline Following too closely & 96 & 0.132 & 62 & 0.203 \\
\hline Using a cell phone & 91 & 0.125 & 109 & 0.357 \\
\hline Failing to give yield & 102 & 0.140 & 37 & 0.121 \\
\hline Changing lane frequently & 83 & 0.114 & 15 & 0.049 \\
\hline Fatigue or illness & 44 & 0.061 & 41 & 0.134 \\
\hline Driving wrong way & 39 & 0.054 & 21 & 0.069 \\
\hline
\end{tabular}

Table 3. Distribution of crashes on each kind of links and intersections

\begin{tabular}{|l|c|c|c|c|c|c|c|c|}
\hline Crash type & Head on & Sideswipes & Rear end & Rollover & CFO & CPB & Others & Total \\
\hline One-lane segments & 5 & 2 & 9 & 2 & 4 & 1 & 0 & 23 \\
\hline Two-lane segments without median & 11 & 7 & 14 & 4 & 6 & 1 & 3 & 46 \\
\hline Four-lane segments without median & 16 & 13 & 29 & 9 & 9 & 0 & 1 & 77 \\
\hline Four-lane segments with median & 5 & 21 & 16 & 1 & 12 & 0 & 2 & 57 \\
\hline Six-lane segments without median & 17 & 29 & 37 & 14 & 21 & 1 & 4 & 123 \\
\hline Six-lane segments with median & 10 & 11 & 22 & 7 & 13 & 0 & 0 & 63 \\
\hline Eight-lane segments & 6 & 14 & 41 & 5 & 15 & 0 & 0 & 81 \\
\hline Three legged intersections (T/Y) & 9 & 17 & 13 & 2 & 7 & 22 & 1 & 71 \\
\hline Four legged intersections (+/x) & 11 & 24 & 21 & 3 & 11 & 39 & 2 & 111 \\
\hline Five legged intersections & 1 & 3 & 2 & 0 & 4 & 4 & 1 & 15 \\
\hline Roundabouts & 2 & 14 & 14 & 0 & 3 & 7 & 0 & 40 \\
\hline Interchanges & 1 & 8 & 5 & 1 & 2 & 0 & 2 & 19 \\
\hline Total & 94 & 163 & 223 & 48 & 107 & 75 & 16 & 726 \\
\hline
\end{tabular}

CFO = collision with fixed objects; $\mathrm{CPB}=$ collision with pedestrians and bicyclists .

In Xi' an city, roundabouts have complex traffic situations and some larger ones are controlled by signals to reduce conflicts between entering vehicles and thus improve safety performance. In this study, 40 crashes $(5.51 \%)$ occurred within roundabouts, mainly referring to slight injuries from side scrapes and minor rear-end/merge collisions. Additionally, 126 crashes happened on four and five legged intersections, accounting for nearly $18 \%$ of all crashes.

\section{Environmental Factors}

In $\mathrm{Xi}$ 'an, the taxi involved traffic crashes remained steady across the years from 2006 to 2012, and the number of licensed vehicles increased slowly during the years from 2009 to 2012, but this period saw an expansion of population (Table 4).

An overwhelming 119 crashes occurred in 2006, and about 100 cases were annually recorded in the following 5 years. At the end of the year 2007, Xi'an carried out a traffic safety improvement project for public transit, aiming at improving the total safety level of buses and taxis through driver's training and specific education as well as implementation of ITS countermeasures. Fortunately, it had achieved a significant success in 2008 and almost all variables decreased over the following three years (Table 4). The average number of crashes per month decreased from 9.917 in 2006 to 7.833 in 2011 and experienced a minimum of 7.750 in 2008 . However, 114 crashes were recorded in the year 2012, partially due to more complex traffic conditions at major segments and intersections under construction of Metro Line 1 and 3 in the city of Xi' an.

Statistics also demonstrate that the taxi safety situation in Xi'an is still a serious concern and will last for a long period. The average number of crashes per 1,000 vehicles also fluctuated between 8.0 and 11.3, and fatal injuries and fatalities crashes including at least one death or severe injury occurred at a daily average from 0.095 to 0.135 , which means approximate one life was lost weekly in taxi crashes. All these facts should be seriously treated.

Table 5 presents the impact of environmental factors on crashes. As expected, 252 and 203 cases occurred on the winter and summer days, respectively, accounting for $34.71 \%$ and $27.96 \%$ of the total observations, due to the influence of snow and rainfall in winter and summer. More seriously, a large proportion of fatal and serious crashes involving taxi vehicles were restrained during these two seasons. In addition, the trends observed confirmed the 
Table 4. Distribution of taxi related crashes from 2006 to 2012

\begin{tabular}{|l|c|c|c|c|c|c|c|}
\hline Year & $\mathbf{2 0 0 6}$ & $\mathbf{2 0 0 7}$ & $\mathbf{2 0 0 8}$ & $\mathbf{2 0 0 9}$ & $\mathbf{2 0 1 0}$ & $\mathbf{2 0 1 1}$ & $\mathbf{2 0 1 2}$ \\
\hline Total crashes & $\mathbf{1 1 9}$ & $\mathbf{1 0 8}$ & 93 & 101 & 97 & 94 & 114 \\
\hline Fatal and serious crashes & $\mathbf{3 9}$ & $\mathbf{4 8}$ & 41 & 34 & 37 & 41 & 48 \\
\hline Number of licensed vehicles & 10,463 & 10,504 & 10,649 & 10,783 & 10,762 & 11,720 & 11,757 \\
\hline Fatal and serious crashes/total crashes & 0.328 & 0.444 & 0.441 & 0.337 & 0.381 & 0.436 & 0.421 \\
\hline Average no. of crashes per month & 9.917 & 9.000 & 7.750 & 8.417 & 8.083 & 7.833 & 9.500 \\
\hline Average no. of crashes per 1,000 vehicles & 11.373 & 10.282 & 8.733 & 9.367 & 9.013 & 8.020 & 9.696 \\
\hline Average no. of vehicles per 1,000 inhabitants & 3.555 & 3.353 & 3.188 & 3.149 & 3.043 & 3.166 & 3.840 \\
\hline
\end{tabular}

concerns of traffic policies relative to weekends, at which more than one third of taxi involved crashes were observed.

Through the further data mining of 726 samples, it is found that the majority of taxi related crashes representing about $48.76 \%$ appeared during the day period from 6 a.m. to 8 p.m. and about $30.72 \%$ of reported crashes occurred at the dangerous nigh period from midnight to 6 a.m. (see Table 5), due to driver's fatigue and sleepiness, lack of effective roadway lighting etc., especially on minor roads and streets and in the winter nights. Particularly, the percentage of fatal and serious crashes at night period was much higher than that at the day time. In addition, $10.74 \%$ and $7.58 \%$ of total crashes occurred at two peak periods from 7 a.m. -9 a.m. and from 5 p.m. -7 p.m., respectively, because more passengers need taxi services at this time, particularly at the morning rush hours. The interval from 8 p.m. to midnight was also a dangerous time for taxi drivers as $20.52 \%$ of the reviewed 726 crashes appeared in this period.

As reported in the previous studies $(2,24)$, it was found that adverse weather conditions are closely associated with the number of taxi crashes and injury severity, when road conditions and visibility are poor.

As shown in Table 5, over $37 \%$ of the reviewed crashes occurred on the rainy, foggy, and snowy days, and nearly $17 \%$ were caused by slipperiness, because wet road surfaces reduce pavement friction and cause skidding or hydroplaning. Moreover, snowy or icy road conditions also dramatically affect the braking distance of a vehicle and pose many challenges for vehicle driving, but almost all drivers will become more cautious during these periods, thus the fatal injuries and fatalities remained at a low level, though in this research the number of taxi involved crashes slightly increased (10.61\%). More seriously, roads without effective lightings are dangerous for driving and 106 out of 726 cases occurred on dark segments or intersections, particularly in road tunnels and underpasses.

\section{DISCUSSION AND CONCLUSIONS}

In this study, taxi involved crashes from 2006-2012 in Xi' an city have been evaluated using the selected 726 samples of the original 7,183 crash reports so as to understand the characteristics of crash occurrence and distribution very well and recommend operational and safety improvement measures of taxi service.

It appears from this study that driver's personnel characteristics, such as gender, age, marital status, education, license status, and driving experience, etc., have an effect on the frequency of
Table 5. Distribution of taxi crashes by environmental impact

\begin{tabular}{|l|c|c|}
\hline Variable & N & $\%$ \\
\hline Season & \multicolumn{2}{|l|}{} \\
\hline Spring & 124 & 17.08 \\
\hline Summer & 203 & 27.96 \\
\hline Autumn & 147 & 20.25 \\
\hline Winter & 252 & 34.71 \\
\hline
\end{tabular}

\begin{tabular}{|l|c|c|}
\hline \multicolumn{2}{|l|}{ Day of week ${ }^{2}$} \\
\hline Weekdays & 472 & 65.01 \\
\hline Weekends & 254 & 34.99 \\
\hline Time of crash \\
\hline 0 am to 6 am & 223 & 30.72 \\
\hline 6 am to 8 pm & 354 & 48.76 \\
\hline 8 pm to 12 pm & 149 & 20.52 \\
\hline Public holiday & \\
\hline Yes & 65 & 8.95 \\
\hline No & 661 & 91.05 \\
\hline Weather conditon
\end{tabular}

Weather condition

\begin{tabular}{|l|l|l|}
\hline Fine & 495 & 68.18 \\
\hline Adverse $^{4}$ & 231 & 31.82 \\
\hline
\end{tabular}

Road surface

\begin{tabular}{|l|c|c|}
\hline Dry & 526 & 72.45 \\
\hline Wet & 123 & 16.94 \\
\hline Snowy/slushy & 64 & 8.82 \\
\hline Icy & 13 & 1.79 \\
\hline
\end{tabular}

\begin{tabular}{|l|l|l|}
\hline \multicolumn{2}{|l|}{ Visibility condition } \\
\hline Good & 587 & 80.85 \\
\hline Bad & 139 & 19.15 \\
\hline Road lighting & \\
\hline Sunlight & 437 & 60.19 \\
\hline Dark-lighted & 183 & 25.21 \\
\hline Dark-unlighted & 106 & 14.60 \\
\hline
\end{tabular}

${ }^{1}$ Spring = March to May; summer = June to August; autumn = September to November: winter $=$ December to February

${ }^{2}$ Weekends $=17: 00$ Friday to 24:00 Sunday; weekdays $=0: 00$ Monday to 16:59 Friday. ${ }^{3}$ New Year, Chinese New Year, Qing Ming Festival, International Labour Day, Dragon Boat Festival, Mid-Autumn Festival, and National Day.

${ }^{4} \mathrm{Heavy}$ rain, fog, snow, and strong wind that can significantly influence the vehicle's operation.

${ }^{5}$ Crashes that occurred within road tunnels and underpasses are classified into the group of dark-lighted and dark-unlighted, respectively, according to the police record. 
taxi crashes and injury severities. The middle aged (77.27\%) male $(91.60 \%)$ drivers with limited education (crash proportion: illiterate $=7.99 \%$; primary school $=16.94 \%$; high school $=43.66 \%$ ) and job experience (crash proportion: $<2$ years $=46.69 \% ; 2-5$ years $=35.81 \%$ ) are much more likely to be involved in a crash. Especially, it was found that the inexperienced taxi drivers with less than five-year experience are far more likely to be involved in a crash (crash proportion: $<3$ years $=31.27 \% ; 3-5$ years $=45.73 \%$ ), because inexperienced drivers are not capable of perceiving the risk ahead, evaluating the danger and making a proper collision avoidance decision. All these require further investigations, aiming at enhancing individual driving capability, understanding why the crashes occur, and making efforts in the reduction or prevention of such crashes.

The trend and pattern of taxi involved crashes varies significantly, depending on the particular time, location and environmental conditions. This study shows that more than $60 \%$ of the total crashes occurred during the winter and summer days as well as weekdays. Additionally, nearly a half of all crashes appeared during the day period from 6 a.m. to 8 p.m. and the periods from midnight to 6 a.m. became the most dangerous time accounting for fatal and serious injuries. Subsequently, it should be pointed out that the proportion of fatal and serious crashes at night period is extremely high compared to the day time. Moreover, adverse weather $(31.82 \%)$, wet pavement surface $(16.94 \%)$, and bad visibility condition (19.15\%) are all found to have significant association with taxi crashes. Poor lighting is another potential problem in tunnels and underpasses, where lights should be installed for safety and to show off the outline of tunnel or underpass itself, or post flashlight-required signs, if permanent lighting is not available. In periods of heavy rain, specially, the lower tunnel or underpass may be filled with puddles and surface water makes driving conditions hazardous; thus a number of warning signs used to alert drivers not to use the tunnel or underpass during high water events are also recommended, particularly in areas prone to flooding.

The statistics indicates that driver's risk behaviour is a major factor contributing to a crash, in which driving over speed limits, safety belt not used and disregarding signs or signals rank the first three types of the most frequently improper or illegal behaviours. Accordingly, the corresponding specific campaign including real time monitoring and educational programmes is urgently needed so as to make the drivers aware of their threat towards other road users and potential danger of being involved in a crash due to improper or illegal behaviours.

For a taxi driver, particularly, vehicle driving is a high-intensity work rather than a flexible one. Long driving hours and long distance traveled daily may put more physical and mental pressure on the drivers that will bring high risk of fatigue, improper/ illegal behaviours and even involvement in a crash. In the city of Xi' an, each taxi driver, on average, traveled 386.4 (SD 105.7) kilometers, worked 9.72 (SD 0.93) hours, completed 33.64 (SD 5.58) trips served daily in the past eight months of 2012, exceeding the official maximum of 8 working hours per day by $21.5 \%$, and worked 6.2 days per week, according to the report from Xi'an Traffic Management Bureau.

Nowadays, taxi drivers' work is the most strenuous, especially at rush hours, in bad weather, and on holidays, but there are few regulations concerning this specific group. Accordingly, the gap between the actual daily working hours and the existing regulations concerning the taxi service should be strictly narrowed so as to protect health and ensure safety. That is, the existing regulations limit the amount of working hours per day to not exceed 8 hours, however, this study found that the taxi drivers work on average 9.72 hours per day, exceeding the official maximum restriction by $21.5 \%$. Each taxi driver is required, on a daily basis, to pay 220-260 CNY to the firm, and so, taxi drivers have to be pushed unconsciously to work as long as possible to make a living. Thus, limiting the continuous driving hours, requiring the rest hours, performing the flexible working hours or irregular shifts, reducing the daily payment to firm, etc., are just the key to address this issue.

There are some important notes from this study useful for the understanding and treating the taxi involved crashes. It is very important, but very difficult, to judge and determine precisely why, when, and how such crash will occur, since the occurrence of crashes is a combined result of several contributory factors. The findings suggest that there is an important role of driver's specific training and education programmes and exploring ITS based management tools and police initiatives for taxi industry, as suggested in our previous studies (25). There is a need for continued or more in-depth discussion on certain topics. Although the issue has not received enough attention in the past, the authors believe that it is important and the further research should focus on the systematic combination of countermeasures targeting the licensing qualification regulations, skills training course, limitation rules for working hours and annual inspection policy, etc.

\section{Acknowledgement}

This research was supported by the Key Programmes of Department of Transport of Shaanxi, China (No. 14-29R). The authors gratefully acknowledge Xi'an Traffic Police for data collection efforts.

\section{Conflict of Interests}

None declared

\section{REFERENCES}

1. The blue book of road safety in China 2011. Beijing: China Communications Press; 2011. (In Chinese.)

2. Lam LT. Environmental factors associated with crash-related mortality and injury among taxi drivers in New South Wales, Australia. Accid Anal Prev. 2004 Sep;36(5):905-8.

3. Donate-López C, Espigares-Rodríguez E, Jiménez-Moleón JJ, Luna-delCastillo Jde D, Bueno-Cavanillas A, Lardelli-Claret P. The association of age, sex and helmet use with the risk of death for occupants of twowheeled motor vehicles involved in traffic crashes in Spain. Accid Anal Prev. 2010 Jan;42(1):297-306.

4. Borowsky A, Oron-Gilad T. Exploring the effects of driving experience on hazard awareness and risk perception via real-time hazard identification, hazard classification, and rating tasks. Accid Anal Prev. 2013 Oct;59:54865.

5. Christoforou Z, Milioti C, Perperidou D, Karlaftis MG. Investigation of taxi travel time characteristics. Adv Transp Stud A. 2012(27):17-30.

6. Firestone RT, Mihaere K, Gander PH. Obstructive sleep apnoea among professional taxi drivers: a pilot study. Accid Anal Prev. 2009 May;41(3):552-6.

7. Maag U, Vanasse C, Dionne G, Laberge-Nadeau C. Taxi drivers' accidents: how binocular vision problems are related to their rate and severity in terms of the number of victims. Accid Anal Prev. 1997 Mar;29(2):217-24.

8. Mann RE, Stoduto G, Ialomiteanu A, Asbridge M, Smart RG, Wickens CM. Self-reported collision risk associated with cannabis use and driv- 
ing after cannabis use among Ontario adults. Traffic Inj Prev. 2010 Apr;11(2):115-22.

9. Hitosugi M, Gomei S, Okubo T, Tokudome S. Sudden illness while driving a vehicle - a retrospective analysis of commercial drivers in Japan. Scand J Work Environ Health. 2012 Jan;38(1):84-7.

10. La QN, Lee AH, Meuleners LB, Van Duong D. Prevalence and factors associated with road traffic crash among taxi drivers in Hanoi, Vietnam. Accid Anal Prev. 2013 Jan;50:451-5.

11. Newnam S, Mamo WG, Tulu GS. Exploring differences in driving behaviour across age and years of education of taxi drivers in Addis Ababa, Ethiopia. Saf Sci. 2014;68:1-5.

12. Dalziel JR, Job RF. Motor vehicle accidents, fatigue and optimism bias in taxi drivers. Accid Anal Prev. 1997 Jul;29(4):489-94.

13. Öz B, Özkan T, Lajunen T. Professional and non-professional drivers' stress reactions and risky driving. Transp Res Part F Traffic Psychol Behav. 2010;13(1):32-40.

14. Routley V, Ozanne-Smith J, Qin Y, Wu M. Taxi driver seat belt wearing in Nanjing, China. J Safety Res. 2009;40(6):449-54.

15. Fleiter JJ, Gao L, Qiu C, Shi K. Availability, functionality, and use of seat belts in Beijing taxis prior to the 2008 Beijing Olympic Games. Accid Anal Prev. 2009 Mar;41(2):342-4

16. Shams M, Shojaeizadeh D, Majdzadeh R, Rashidian A, Montazeri A. Taxi drivers' views on risky driving behavior in Tehran: a qualitative study using a social marketing approach. Accid Anal Prev. 2011 May;43(3):64651.

17. Sullman MJ, Stephens AN, Kuzu D. The expression of anger amongst Turkish taxi drivers. Accid Anal Prev. 2013 Jul;56:42-50.
18. Chin HC, Huang HL. Safety assessment of taxi drivers in Singapore. Transp Res Rec. 2009;2114:47-56.

19. Tseng CM. Operating styles, working time and daily driving distance in relation to a taxi driver's speeding offenses in Taiwan. Accid Anal Prev. 2013 Mar;52:1-8.

20. Wang YG, Huang SS, Xiang WS, Pei YL. Multipattern road traffic crashes and injuries: a case study of Xi'an city. Acta Polytech Hung. 2011;8(4):171-81.

21. Brookland R, Begg D. Adolescent, and their parents, attitudes towards graduated driver licensing and subsequent risky driving and crashes in young adulthood. J Safety Res. 2011 Apr;42(2):109-15.

22. Lyon JD, Pan R, Li J. National evaluation of the effect of graduated driver licensing laws on teenager fatality and injury crashes. J Safety Res. 2012 Feb;43(1):29-37.

23. De Lucca M, Dell'Acqua G. Freeway safety management: case studies in Italy. Transport. 2012;27(3):320-6.

24. Jung S, Qin X, Noyce DA. Injury severity of multivehicle crash in rainy weather. J Transp Eng. 2012;138(1):50-9.

25. Wang YC, Li LC, Feng L, Peng H. Professional drivers' views on risky driving behaviors and accident liability: a questionnaire survey in Xining, China. Transp Lett. 2014;6(3):126-35.

Received June 11, 2013 Accepted in revised form September 15, 2014 